\title{
Accuracy of Cardiac Output by Nine Different Pulse Contour Algorithms in Cardiac Surgery Patients: A Comparison with Transpulmonary Thermodilution
}

\author{
Ole Broch, ${ }^{1}$ Berthold Bein, ${ }^{2}$ Matthias Gruenewald, ${ }^{1}$ Sarah Masing, \\ Katharina Huenges, ${ }^{3}$ Assad Haneya, ${ }^{3}$ Markus Steinfath, ${ }^{1}$ and Jochen Renner ${ }^{1}$ \\ ${ }^{1}$ Department of Anesthesiology and Intensive Care Medicine, University Hospital Schleswig-Holstein, \\ Campus Kiel, Schleswig-Holstein, Germany \\ ${ }^{2}$ Department of Anesthesiology and Intensive Care Medicine, Asklepios Hospital St. Georg, Hamburg, Germany \\ ${ }^{3}$ Department of Cardiothoracic and Vascular Surgery, University Hospital Schleswig-Holstein, \\ Campus Kiel, Schleswig-Holstein, Germany
}

Correspondence should be addressed to Ole Broch; ole.broch@uksh.de

Received 26 July 2016; Revised 9 November 2016; Accepted 22 November 2016

Academic Editor: Kazunori Uemura

Copyright (C) 2016 Ole Broch et al. This is an open access article distributed under the Creative Commons Attribution License, which permits unrestricted use, distribution, and reproduction in any medium, provided the original work is properly cited.

\begin{abstract}
Objective. Today, there exist several different pulse contour algorithms for calculation of cardiac output (CO). The aim of the present study was to compare the accuracy of nine different pulse contour algorithms with transpulmonary thermodilution before and after cardiopulmonary bypass (CPB). Methods. Thirty patients scheduled for elective coronary surgery were studied before and after CPB. A passive leg raising maneuver was also performed. Measurements included CO obtained by transpulmonary thermodilution $\left(\mathrm{CO}_{\mathrm{TPTD}}\right)$ and by nine pulse contour algorithms $\left(\mathrm{CO}_{\mathrm{X} 1-9}\right)$. Calibration of pulse contour algorithms was performed by esophageal Doppler ultrasound after induction of anesthesia and $15 \mathrm{~min}$ after CPB. Correlations, Bland-Altman analysis, fourquadrant, and polar analysis were also calculated. Results. There was only a poor correlation between $\mathrm{CO}_{\mathrm{TPTD}}$ and $\mathrm{CO}_{\mathrm{X} 1-9}$ during passive leg raising and in the period before and after CPB. Percentage error exceeded the required 30\% limit. Four-quadrant and polar analysis revealed poor trending ability for most algorithms before and after $\mathrm{CPB}$. The Liljestrand-Zander algorithm revealed the best reliability. Conclusions. Estimation of $\mathrm{CO}$ by nine different pulse contour algorithms revealed poor accuracy compared with transpulmonary thermodilution. Furthermore, the less-invasive algorithms showed an insufficient capability for trending hemodynamic changes before and after $\mathrm{CPB}$. The Liljestrand-Zander algorithm demonstrated the highest reliability. This trial is registered with NCT02438228 (ClinicalTrials.gov).
\end{abstract}

\section{Introduction}

Since several years, less-invasive methods like pulse contour analysis or esophageal Doppler for estimation of cardiac output (CO) or stroke volume (SV) have been more and more established in daily clinical routine. At present, these devices are used for hemodynamic optimization of different highrisk patient collectives undergoing major surgical procedures [1-3]. Moreover, some of these monitoring systems have been implemented in national guidelines dealing with goal directed therapy [4]. In this context, several investigations were able to demonstrate that monitoring and optimization of hemodynamic variables like $\mathrm{CO}$ were associated with a significant lower rate of postoperative morbidity and mortality [5]. In the past, estimation of $\mathrm{CO}$ was mostly performed by thermodilution, often associated with considerable complications and lack of beneficial effects $[6,7]$. Therefore, alternative lessinvasive monitoring systems like esophageal Doppler or pulse contour analysis have gained increasing interest. Similar to the esophageal Doppler devices, less-invasive and quick available pulse contour monitoring systems were originally developed to determine beat-to-beat $\mathrm{CO}$ without the need for calibration. Due to the lack of serious complications and missing interobserver variability, these devices could 
be extremely valuable for the clinician in daily clinical practice [8]. Besides esophageal Doppler monitoring, a recent study could demonstrate that many clinicians use pulse contour analysis for estimation of $\mathrm{CO}$ in patients undergoing high-risk surgery [9]. However, measurements of absolute CO by Doppler or pulse contour analysis were claimed to be more imprecise compared to thermodilution [10-12]. There exist a wide variety of less-invasive or noninvasive monitoring systems based on pulse contour analysis. Every system consists of a special software algorithm and most of them are based on the findings by Otto Frank [13]. For the calculation of $\mathrm{CO}$, these proprietary software algorithms compute the individual aortic compliance and systemic vascular resistance (SVR) based on specific patient data such as age, height, weight, and gender. The nine different pulse contour algorithms investigated were the mean pressure model (X1), the Windkessel (X2), and the Windkessel with RC Decay model (X3), the Liljestrand-Zander model (X4), the Pressure Root Mean Square model (X5), the Herd model (X6), the systolic area (X7), the systolic area with correction (X8), and the systolic area with corrected impedance model (X9). However, data concerning the reliability of these nine algorithms are rare and were investigated in different patient collectives. Therefore, the aim of the present observational study was to investigate the accuracy and trending ability of $\mathrm{CO}$ by nine different pulse contour algorithms $\left(\mathrm{CO}_{\mathrm{X} 1-9}\right)$ calibrated by esophageal Doppler and compared with CO by transpulmonary thermodilution $\left(\mathrm{CO}_{\mathrm{TPTD}}\right)$ before and after cardiopulmonary bypass $(\mathrm{CPB})$.

\section{Materials and Methods}

After approval from institutional ethics committee (Ethikkommission UKSH Kiel - AZ: A128/02, Christian-AlbrechtsUniversity Kiel, Schwanenweg 20, D 24105 Kiel), written informed consent for participation in the study was obtained preoperatively from all patients. The trial was registered on ClinicalTrials.gov (NCT02438228) and conducted in compliance with the Helsinki Declaration. Thirty patients undergoing elective coronary artery bypass grafting (CABG) were studied after induction of general anesthesia until discharge to the intensive care unit. Patients less than 18 years of age, with a left ventricular ejection fraction $\leq 0.5$, and with a lack of sinus rhythm were excluded. Further exclusion criteria were esophageal malformations and valvular heart diseases and emergency procedures and patients requiring mechanical support or continuous high-dose $(>0.1 \mu \mathrm{g} / \mathrm{kg} / \mathrm{min})$ catecholamine therapy.

2.1. Algorithms. The nine different pulse contour algorithms were described in detail elsewhere $[14,15]$. In brief, X1 (SV = $K \times$ MAP) calculates CO in analogy to Ohm's law from mean arterial pressure (MAP) and SVR. X2 (SV $=K \times$ $(\mathrm{SBP}-\mathrm{DBP}) \times \mathrm{HR})$ is based on the Windkessel model while taking into account the fact that arteries are capable of storing blood. X3 $(\mathrm{SV}=K \times(\mathrm{MAP} / 60) \times \ln (\mathrm{SBP} / \mathrm{DBP}) \times \mathrm{HR})$ is the Windkessel with RC Decay model which calculates the time constant of the Windkessel circuit model as an exponential decay from systolic to diastolic pressure. X4
$(\mathrm{SV}=K \times(\mathrm{SBP}-\mathrm{DBP}) /(\mathrm{SBP}+\mathrm{DBP}) \times \mathrm{HR})$ is based on the Liljestrand-Zander model considering the nonlinearity between pressure, arterial compliance, and capacitance of blood. X5 $\left(\mathrm{SV}=K \times \sqrt{ }\left[\int_{t}\left(\mathrm{ABP}_{(t)}-\mathrm{MAP}\right)^{2} d t\right] \times \mathrm{HR}\right)$ represents the Pressure Root Mean Square model which assumes that $\mathrm{SV}$ is proportional to root-mean-square of each cycle in the arterial waveform. Root-mean-square of each waveform is thought to be proportional to power and, moreover, SV and power are linearly related. $\mathrm{X} 6(\mathrm{SV}=K \times(\mathrm{MAP}-\mathrm{DBP}) \times$ HR) stands for the Herd model which proposes that SV is proportional to the difference between mean and diastolic pressure. $\mathrm{X} 7\left(\mathrm{SV}=K \times \int_{\text {sys }} \mathrm{ABP}(d t) \times \mathrm{HR}\right.$ ) is based on the systolic area model where SV is proportional to the systolic area of the arterial waveform. X8 $\left(\mathrm{SV}=K \times\left(1+T_{\mathrm{sys}} / T_{\mathrm{dia}}\right) \times\right.$ $\left.\int_{\text {sys }} \mathrm{ABP}(d t) \times \mathrm{HR}\right)$ is the systolic area with correction model which applies a correction factor for compensating duration of systole. X9 $(\mathrm{SV}=K \times(163+\mathrm{HR}-0.48 \times \mathrm{MAP}) \times$ $\left.\int_{\text {sys }} \mathrm{ABP}(d t) \times \mathrm{HR}\right)$ is the systolic area with corrected impedance using another correction factor based on empirical evidence (Table 1).

2.2. Study Protocol. All patients received oral premedication with midazolam $0.1 \mathrm{mg} / \mathrm{kg} 30$ minutes before operation. After establishing the standard monitoring which included pulse oximetry and a 5-lead ECG, patients received peripheral venous access and a radial arterial line in Seldingertechnique (Arrow International, Inc., Reading, PA, USA). Subsequently, the arterial transducer was adjusted as advised by the manufacturer. Thereafter, induction of anesthesia was performed. A central venous catheter and a transpulmonary thermodilution catheter (Pulsion Medical Systems, Munich, Germany) were introduced in the right internal jugular vein and in the femoral artery, respectively. An esophageal Doppler probe was inserted via the nose and connected to a research monitor with a proprietary algorithm which used nine different pulse contour algorithms and the radial artery signal (Deltex Medical Ltd., Chichester, UK). Ventilation was performed with the ADU S5 ventilator (Datex Ohmeda, GE Healthcare, Munich, Germany) in a volume-controlled mode with a tidal volume of $6-8 \mathrm{~mL} / \mathrm{kg}$, a positive end-expiratory pressure of $5 \mathrm{~cm} \mathrm{H}_{2} \mathrm{O}$, an I: $\mathrm{E}$ ratio of $1: 1.5$, and a $\mathrm{FiO}_{2}$ of 0.5 . Respiratory rate was adjusted to achieve normocapnia $\left(\mathrm{pCO}_{2}\right.$ $35-40 \mathrm{mmHg}$ ) and end-tidal carbon dioxide was measured with an infrared absorption analyzer. The thermodilution catheter was connected to the $\mathrm{PiCCO}_{2}$ monitor (software version 1.3.0.8).

2.3. Data Collection. After induction of anesthesia and establishment of all monitoring devices, the nine different pulse contour algorithms were calibrated by esophageal Doppler before starting operation. Thereafter, a passive leg raising maneuver was performed and hemodynamic variables including $\mathrm{CO}\left(\mathrm{CO}_{\mathrm{TPTD}}, \mathrm{CO}_{\mathrm{X} 1-9}\right)$ were recorded before, during, and after passive leg raising. This maneuver was performed by a leg elevation up to $45^{\circ}$ with the trunk in the horizontal position which induced hemodynamic changes by transferring blood from peripheral towards central compartments [16]. Due to various reasons like short time period 
TABLE 1: Pulse contour algorithms used in the study $[14,15]$.

\begin{tabular}{lcc}
\hline Number & Model's name & Algorithm \\
\hline X1 & Mean arterial pressure model & $\mathrm{SV}=K \times \mathrm{MAP}$ \\
$\mathrm{X} 2$ & Windkessel model & $\mathrm{SV}=K \times(\mathrm{SBP}-\mathrm{DBP}) \times \mathrm{HR}$ \\
$\mathrm{X} 3$ & Windkessel with RC Decay model & $\mathrm{SV}=K \times(\mathrm{MAP} / 60) \times \ln (\mathrm{SBP} / \mathrm{DBP}) \times \mathrm{HR}$ \\
$\mathrm{X} 4$ & Liljestrand-Zander model & $\mathrm{SV}=K \times(\mathrm{SBP}-\mathrm{DBP}) /(\mathrm{SBP}+\mathrm{DBP}) \times \mathrm{HR}$ \\
$\mathrm{X} 5$ & Pressure Root Mean Square model & $\mathrm{SV}=K \times \sqrt{ }\left[\int_{t}(\mathrm{ABP}(t)-\mathrm{MAP})^{2} d t\right] \times \mathrm{HR}$ \\
$\mathrm{X} 6$ & Herd model & $\mathrm{SV}=K \times(\mathrm{MAP}-\mathrm{DBP}) \times \mathrm{HR}$ \\
$\mathrm{X} 7$ & $\mathrm{Systolic}$ area model & $\mathrm{SV}=K \times \int_{\text {sys }} \mathrm{ABP}(d t) \times \mathrm{HR}$ \\
$\mathrm{X} 8$ & Systolic area with correction & $\mathrm{SV}=K \times\left(1+T_{\text {sys }} / T_{\text {dia }}\right) \times \int_{\text {sys }} \mathrm{ABP}(d t) \times \mathrm{HR}$ \\
$\mathrm{X} 9$ & Systolic area with corrected impedance & $\mathrm{SV}=K \times(163+\mathrm{HR}-0,48 \times \mathrm{MAP}) \times \int_{\text {sys }} \mathrm{ABP}(d t) \times \mathrm{HR}$ \\
\hline
\end{tabular}

SV, stroke volume; HR, heart rate; MAP, mean arterial pressure; SBP, systolic blood pressure; DBP, diastolic blood pressure; ABP, arterial blood pressure; $T$, duration of cardiac cycle $(T=\sqrt{ } \mathrm{HR} / 60) ; T_{\text {sys }}$, duration of systole (estimated as $30 \%$ of $\left.T\right)$; $T_{\text {dia }}$, duration of diastole $\left(T_{\text {dia }}=T-T_{\text {sys }}\right)$.

available and process organization, we performed a passive leg raising maneuver in 21 patients. Subsequently, estimation of $\mathrm{CO}_{\mathrm{TPTD}}$ and $\mathrm{CO}_{\mathrm{X} 1-9}$ was carried out every 10 minutes until the beginning of $\mathrm{CPB}(\mathrm{T} 1)$. Estimation of $\mathrm{CO}_{\mathrm{X} 1-9}$ was performed using screenshots simultaneously by recording and averaging three values over a period of one minute. Due to different experiences of the surgeons and time needed for preparation, number of measurements differed from patient to patient. Unconditional requirements for the measurements during the whole study period were stable hemodynamic conditions and exclusion of an under- or overdamped arterial signal. $\mathrm{CO}_{\text {TPTD }}$ was estimated by injecting $15 \mathrm{~mL}$ ice-cold saline $\left(\leq 8^{\circ} \mathrm{C}\right)$ at least three times through the central venous line. Measurements were repeated if CO between individual measurements differed $\geq 15 \%$. Fifteen minutes after weaning from $\mathrm{CPB}$, calibration of the nine different pulse contour algorithms was carried out again and estimation of $\mathrm{CO}_{\mathrm{TPTD}}$ and $\mathrm{CO}_{\mathrm{X} 1-9}$ was restarted up to the end of the surgical intervention (T2). In this context, it must be emphasized that accuracy of transpulmonary thermodilution could be impaired due to transient thermal changes especially after CPB [17]. Again, due to different time needed for surgery, number of measurement pairs in individual patients differed during this time period. Study design is displayed in Figure 1. There was no deviation from the study protocol.

2.4. Statistical Analysis. Commercially available statistics software was used for statistical comparisons (GraphPad Prism 5, GraphPad Software Inc., San Diego, CA, USA; MedCalc for Windows, version 11.6.1.0, MedCalc Software, Mariakerke, Belgium; SigmaPlot 12.5 for Windows version 7, Systat Software, Inc., San Jose, CA). For demonstration of the relationship between sample size and the width of the confidence interval of the estimated variable, we calculated the width of the $95 \%$ confidence interval of the limits of agreement $( \pm 2.093 \sqrt{3 / n} \cdot s$, where $s$ is the standard deviation of the bias) as recommended by Bland and Altman (0.66 standard deviations of the bias) [18]. All data are given as mean \pm $\mathrm{SD}$ and a $p$ value $<0.05$ was considered significant. Linear correlations between the measurements of $\mathrm{CO}_{\text {TPTD }}$ and $\mathrm{CO}_{\mathrm{X} 1-9}$ were calculated. Bland-Altman analysis for repeated measurements was performed to plot the agreement between $\mathrm{CO}_{\text {TPTD }}$ and $\mathrm{CO}_{\mathrm{X} 1-9}$ for each time period (T1-T2). The limits of agreement (2SD) of the bias divided by the mean CO values from $\mathrm{CO}_{\mathrm{TPTD}}$ and $\mathrm{CO}_{\mathrm{X} 1-9}$ were used for calculation of the percentage error and a 30\% threshold was determined as suggested by recent literature [19]. The trending ability was described by using different statistical techniques like determination of correlation coefficients between $\Delta \mathrm{CO}_{\mathrm{TPTD}}$ and $\Delta \mathrm{CO}_{\mathrm{X} 1-9}(\Delta \mathrm{CO}$ representing the change between sequential readings), four-quadrant analysis, and polar plot analysis [11]. The concordance using the change in $\mathrm{CO}$ between $\triangle \mathrm{CO}_{\mathrm{TPTD}}$ and $\Delta \mathrm{CO}_{\mathrm{X} 1-9}$ was estimated. As recommended by Critchley and colleagues, changes of $\mathrm{CO}_{\mathrm{TPTD}}<15 \%$ were excluded from further analysis and a concordance rate of $>92 \%$ was considered as sufficient trending ability [20]. With respect to polar analysis, mean change in $\mathrm{CO}$ was reflected by the distance from the center of the polar plots. As suggested by Critchley and colleagues, we have used the average $\Delta \mathrm{CO}$ value as the radius, because true changes in $\mathrm{CO}$ were better represented by mean $\Delta \mathrm{CO}$ [20]. Similar to the Bland-Altman plots, data points within the $10 \%$ limits of agreement (10\% LOAs) indicated good trending ability and data pairs within the $20 \%$ LOAs indicated acceptable trending. Concordance rates $>92 \%$ were considered sufficient [20]. To analyze significant differences of hemodynamic variables related to the periods of measurement, an unpaired sample $t$-test was used.

\section{Results}

Data of all 30 patients, 19 males and 11 females, were included into final analysis. No complication in context of the present study was observed. Patient's age ranged between 32 and 83 years, with a mean age of $69 \pm 3$ years and a mean body mass index of $27.5 \pm 2.7 \mathrm{~kg} / \mathrm{m}^{2}$. Mean left ventricular ejection fraction was $0.61 \pm 0.07$. A total of 279 data pairs (T1: 159, T2: 120) were obtained during the study period. Unpaired $t$ test showed a significant difference $(p<0.05)$ between SVR, heart rate, and $\mathrm{CO}\left(\mathrm{CO}_{\mathrm{TPTD}}, \mathrm{CO}_{\mathrm{X} 1-9}\right)$ before (T1) and after CPB (T2). Hemodynamic variables are shown in Table 2.

We observed a moderate correlation between $\mathrm{CO}_{\mathrm{TPTD}}$ and $\mathrm{CO}$ by esophageal Doppler $\left(\mathrm{CO}_{\mathrm{ED}}\right)$ before $\left(r^{2}=0.50\right.$, 


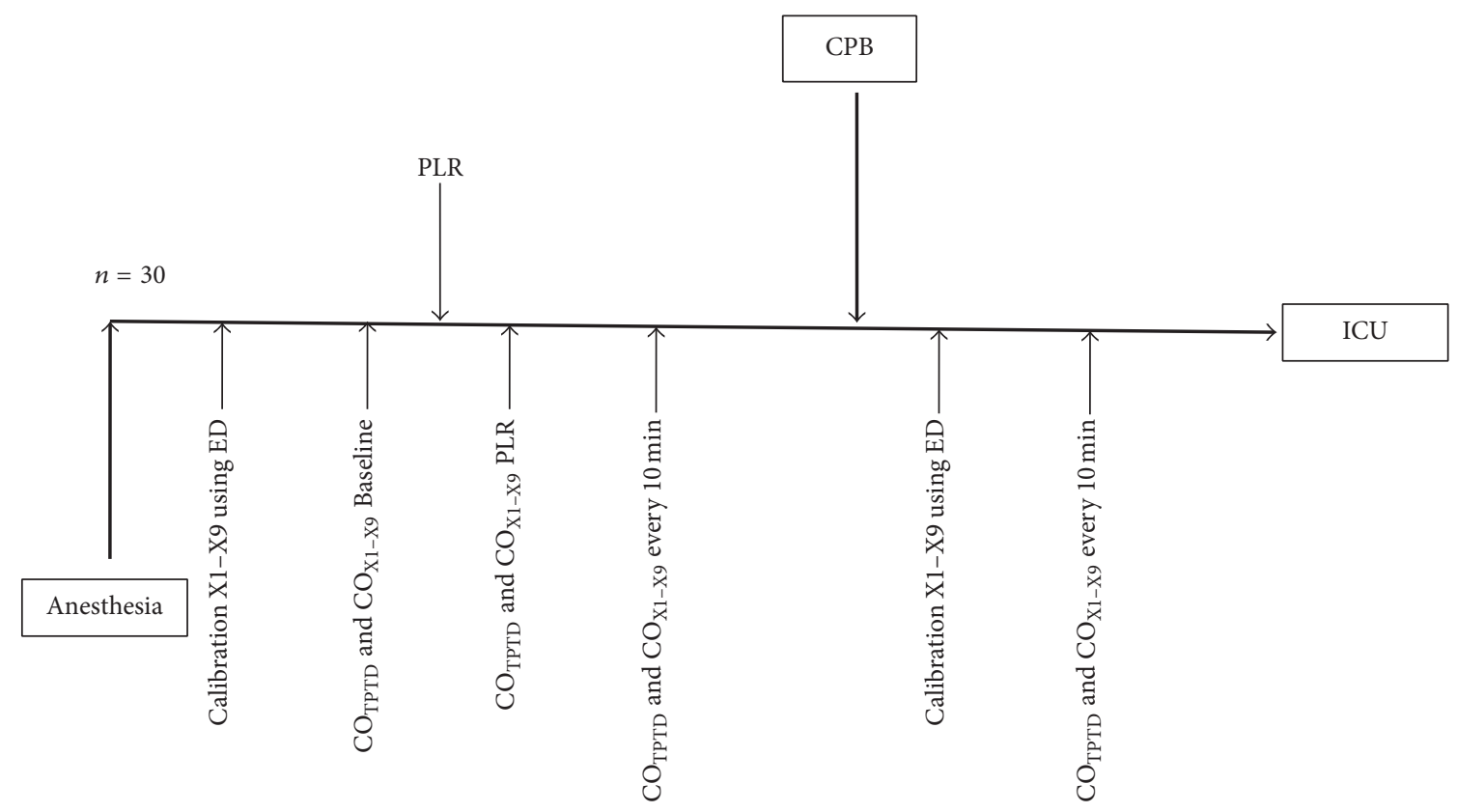

FIGURE 1: Illustration of Study Design. After induction of anesthesia, calibration of nine different pulse contour algorithms (X1-X9) was carried out with esophageal Doppler (ED). Data collection of cardiac output by transpulmonary thermodilution $\left(\mathrm{CO}_{\mathrm{TPTD}}\right)$ and by nine pulse contour algorithms $\left(\mathrm{CO}_{\mathrm{X} 1-9}\right)$ was performed before, during, and after passive leg raising (PLR). Following PLR, measurements of $\mathrm{CO}_{\mathrm{TPTD}}$ and $\mathrm{CO}_{\mathrm{X} 1-9}$ before and after cardiopulmonary bypass (CPB) were repeated every $10 \mathrm{~min}$.

TABLE 2: Hemodynamic variables before and after cardiopulmonary bypass.

\begin{tabular}{|c|c|c|c|}
\hline \multirow[b]{2}{*}{ Variables } & \multirow{2}{*}{$\begin{array}{c}\text { Before CPB } \\
\quad \mathrm{T} 1 \\
n=159\end{array}$} & \multicolumn{2}{|c|}{ After CPB } \\
\hline & & $\begin{array}{c}\mathrm{T} 2 \\
n=120\end{array}$ & $p$ \\
\hline $\mathrm{HR}\left(\mathrm{min}^{-1}\right)$ & $53 \pm 2$ & $82 \pm 5$ & $p<0.05^{\#}$ \\
\hline MAP (mmHg) & $75 \pm 9$ & $74 \pm 10$ & $p=0.92$ \\
\hline SAP (mmHg) & $116 \pm 13$ & $116 \pm 14$ & $p=0.86$ \\
\hline DAP (mmHg) & $59 \pm 12$ & $58 \pm 11$ & $p=0.52$ \\
\hline CVP (mmHg) & $11 \pm 3$ & $12 \pm 2$ & $p=0.17$ \\
\hline $\mathrm{SVR}_{\mathrm{TPTD}}\left(\right.$ dynes$\left.\cdot \mathrm{s} / \mathrm{cm}^{5}\right)$ & $2370 \pm 62$ & $1968 \pm 121$ & $p<0.05^{\#}$ \\
\hline $\mathrm{CO}_{\mathrm{TPTD}}(\mathrm{L} / \mathrm{min})$ mean & $3.8 \pm 0.9$ & $5.7 \pm 1.1$ & $p<0.05^{\#}$ \\
\hline $\mathrm{CO}_{\mathrm{ED}}(\mathrm{L} / \mathrm{min})$ mean & $3.2 \pm 1.2$ & $5.2 \pm 1.9$ & $p<0.05^{\#}$ \\
\hline $\mathrm{CO}_{\mathrm{X} 1}(\mathrm{~L} / \mathrm{min})$ mean & $2.8 \pm 0.9$ & $5.6 \pm 2.4$ & $p<0.05^{\#}$ \\
\hline $\mathrm{CO}_{\mathrm{X} 2}(\mathrm{~L} / \mathrm{min})$ mean & $3.1 \pm 1.0$ & $5.5 \pm 2.3$ & $p<0.05^{\#}$ \\
\hline $\mathrm{CO}_{\mathrm{X} 3}(\mathrm{~L} / \mathrm{min})$ mean & $3.1 \pm 0.9$ & $5.6 \pm 2.4$ & $p<0.05^{\#}$ \\
\hline $\mathrm{CO}_{\mathrm{X} 4}(\mathrm{~L} / \mathrm{min})$ mean & $3.4 \pm 1.2$ & $5.4 \pm 2.1$ & $p<0.05^{\#}$ \\
\hline $\mathrm{CO}_{\mathrm{X} 5}(\mathrm{~L} / \mathrm{min})$ mean & $3.2 \pm 1.2$ & $5.5 \pm 2.1$ & $p<0.05^{\#}$ \\
\hline $\mathrm{CO}_{\mathrm{X} 6}(\mathrm{~L} / \mathrm{min})$ mean & $3.1 \pm 1.1$ & $5.6 \pm 2.4$ & $p<0.05^{\#}$ \\
\hline $\mathrm{CO}_{\mathrm{X} 7}(\mathrm{~L} / \mathrm{min})$ mean & $2.9 \pm 1.0$ & $5.7 \pm 2.4$ & $p<0.05^{\#}$ \\
\hline $\mathrm{CO}_{\mathrm{X} 8}(\mathrm{~L} / \mathrm{min})$ mean & $2.9 \pm 0.9$ & $5.7 \pm 2.5$ & $p<0.05^{\#}$ \\
\hline $\mathrm{CO}_{\mathrm{X} 9}(\mathrm{~L} / \mathrm{min})$ mean & $3.0 \pm 1.0$ & $5.7 \pm 2.5$ & $p<0.05^{\#}$ \\
\hline
\end{tabular}

$\mathrm{CPB}$, cardiopulmonary bypass; HR, heart rate; MAP, mean arterial pressure; SAP, systolic arterial pressure; DAP, diastolic arterial pressure; CVP, central venous pressure; $\mathrm{SVR}_{\mathrm{TPTD}}$, systemic vascular resistance index measured by transpulmonary thermodilution; $\mathrm{CO}_{\mathrm{TPTD}}$, cardiac output by transpulmonary thermodilution; $\mathrm{CO}_{\mathrm{ED}}$, cardiac output by esophageal doppler; $\mathrm{CO}_{\mathrm{X} 1-9}$, cardiac output by nine different pulse contour algorithms; Values are given as mean \pm SD. ${ }^{\#} p<0.05$ (versus T1). 
$p<0.0001)$ and after $\left(r^{2}=0.64, p<0.0001\right)$ CPB. BlandAltman analysis for $\mathrm{CO}_{\mathrm{ED}}$ showed a mean bias of $-0.49 \mathrm{~L} / \mathrm{min}$ with $95 \%$ limits of agreement (95\% LOAs) from -1.92 to $0.93 \mathrm{~L} / \mathrm{min}$ and a percentage error of $40 \%$ before CPB. After $\mathrm{CPB}, \mathrm{CO}_{\mathrm{ED}}$ showed a mean bias of $-0.44 \mathrm{~L} / \mathrm{min}, 95 \% \mathrm{LOAs}$ from -2.60 to $1.72 \mathrm{~L} / \mathrm{min}$, and a percentage error of $35 \%$.

There was a poor but significant correlation between $\mathrm{CO}_{\mathrm{TPTD}}$ and $\mathrm{CO}_{\mathrm{X} 1-9}$ at $\mathrm{T} 1$ ranging from $r^{2}=0.10$ to 0.36 with $p<0.0001$. At T2, correlation ranged from $r^{2}=0.42$ to 0.56 with $p<0.0001$ (Table 2). Algorithm X4 (LiljestrandZander) showed the highest correlation with $r^{2}=0.36$ and $p<0.0001$ before and $r^{2}=0.56$ and $p<0.0001$ after CPB. Bland-Altman analysis for $\mathrm{CO}_{\mathrm{TPTD}}$ and $\mathrm{CO}_{\mathrm{X} 1-9}$ with bias, 95\% LOAs, and percentage error before and after CPB is represented in Table 3.

There was a weak correlation between $\mathrm{CO}_{\mathrm{X} 1-9}$ and SVR determined by transpulmonary thermodilution ( $\mathrm{SVR}_{\mathrm{TPTD}}$ ) at T1 ranging from $r^{2}=0.04$ to $0.18, p<0.0001$, and from $r^{2}=$ 0.29 to $0.42, p<0.0001$, at $\mathrm{T} 2$.

A passive leg raising maneuver before $\mathrm{CPB}$ was performed in 21 patients. Patients who increased their $\mathrm{SVR}_{\mathrm{TPTD}}>$ $15 \%$ during passive leg raising were defined as responders. During passive leg raising, $\mathrm{CO}_{\mathrm{ED}}$ revealed a correlation of $r^{2}=0.38, p<0.0001$, a mean bias of $-0.34 \mathrm{~L} / \mathrm{min}, 95 \%$ LOAs from -2.15 to $1.47 \mathrm{~L} / \mathrm{min}$, and a percentage error of $59 \%$.

We observed 9 responders $(43 \%)$ and there was a poor but significant correlation between $\mathrm{CO}_{\mathrm{TPTD}}$ and $\mathrm{CO}_{\mathrm{X} 1-9}\left(r^{2}=\right.$ 0.15 to $0.36, p<0.0001)$. During passive leg raising, BlandAltman analysis showed a mean bias ranging from -0.34 to $-0.54 \mathrm{~L} / \mathrm{min}$. Correlations and Bland-Altman analysis during passive leg raising are represented in Table 4.

As suggested by recent literature, percentage changes $<15 \%$ were excluded from further analysis [20]. Correlation coefficients between $\Delta \mathrm{CO}_{\mathrm{TPTD}}$ and $\Delta \mathrm{CO}_{\mathrm{X} 1-9}$ and modified Bland-Altman analysis before and after CPB showed a poor trending ability with wide 95\% LOAs for all pulse contour algorithms (Supplement A, in Supplementary Material available online at http://dx.doi.org/10.1155/2016/3468015). Without exception, four-quadrant plots revealed a concordance rate $<90 \%$ indicating poor ability for reflecting hemodynamic changes before $\mathrm{CPB}$. After $\mathrm{CPB}$, four-quadrant analysis showed a good concordance rate of $95 \%$ for X4. All other algorithms demonstrated poor to moderate trending ability (Figures 2(a) and 2(b)). Polar analysis demonstrated a poor to moderate trending ability before CPB (data within 10\% LOAs: 59-86\%, 20\% LOAs: 80-94\%) and after CPB (data within 10\% LOAs: $42-68 \%$, 20\% LOAs: $76-89 \%$ ) for mean $\Delta \mathrm{CO}_{\mathrm{X} 1-9}$ (Table 5).

There was no significant correlation between MAP, $\mathrm{CO}_{\mathrm{X} 1-9}$, and $\mathrm{CO}_{\mathrm{TPTD}}$ before and after $\mathrm{CPB}$.

\section{Discussion}

To the best of our knowledge, this is the first study investigating nine different pulse contour algorithms compared with transpulmonary thermodilution in patients undergoing cardiac surgery. The results of our study demonstrated that none of the nine different pulse contour algorithms calibrated by esophageal Doppler was able to reliably measure CO compared with transpulmonary thermodilution during the whole study period. Algorithm X4, based on the Liljestrand-Zander model, revealed the best correlation and percentage error. With respect to hemodynamic changes, the pulse contour algorithms mainly revealed a poor ability to reflect variations in $\mathrm{CO}$ before and after $\mathrm{CPB}$. Again, the Liljestrand-Zander model demonstrated the best agreement with transpulmonary thermodilution especially after CPB.

In the last years, less-invasive methods for estimation of CO like pulse contour analysis have gained increasing acceptance in daily clinical routine $[8,9]$. These monitoring systems are mainly characterised by simple handling and quick availability in contrast to thermodilution measurements, which are time-consuming and frequently associated with severe method related complications [21]. After input of patient specific data, pulse contour analysis delivers continuous, uncalibrated $\mathrm{CO}$ and other variables, enabling the clinician to respond quickly and efficiently to hemodynamic changes. This could be advantageous, as a recent multicenter investigation highlighted the importance of proper assessment of moderate risk to high-risk patients undergoing elective surgery [22]. Furthermore, the beneficial effects of early goal directed therapy based on hemodynamic variables like CO have been demonstrated repeatedly in numerous different patient collectives $[2,5,23,24]$.

Today, various less-invasive or noninvasive devices based on pulse contour analysis are offered for sale. However, each device is based on a proprietary software algorithm, which in turn is derived from the findings by Otto Frank [13].

The recently introduced CardioQ-ODM+ monitoring system (Deltex Medical Ltd., Chichester, UK) consists of an esophageal Doppler in combination with pulse contour analysis based on the Liljestrand-Zander model. Similar to the $\mathrm{PiCCO}_{2}$ (Pulsion Medical Systems, Munich, Germany) or EV1000 (Edwards Lifesciences LLC, Irvine, CA, USA) monitoring systems which combine thermodilution and pulse contour analysis, the Doppler device can be used for calibration of the pulse contour algorithm. This is of high clinical importance, because several studies demonstrated increasing lack of accuracy for uncalibrated pulse contour analysis in presence of changes in vascular tone [11,25]. With respect to our study comparing nine different pulse contour algorithms with transpulmonary thermodilution, we mainly observed a poor correlation between $\mathrm{CO}_{\mathrm{TPTD}}$ and $\mathrm{CO}_{\mathrm{X} 1-9}$ with high bias and 95\% LOAs and a percentage error significantly above the required $30 \%$ limit. A possible explanation of these results could be the frequency of calibration of the different pulse contour algorithms. As we performed only single calibration by esophageal Doppler once before and after $\mathrm{CPB}$, this might have resulted in significant inaccuracies regarding estimation of pulse contour CO. This hypothesis is supported by recent studies, which demonstrated increasing inaccuracy for pulse contour analysis in presence of hemodynamic changes due to an insufficient number of recalibrations $[26,27]$. Furthermore, it is well known that on-pump cardiac surgery is associated with significant hemodynamic changes before and after CPB and sets great demands on the reliability 


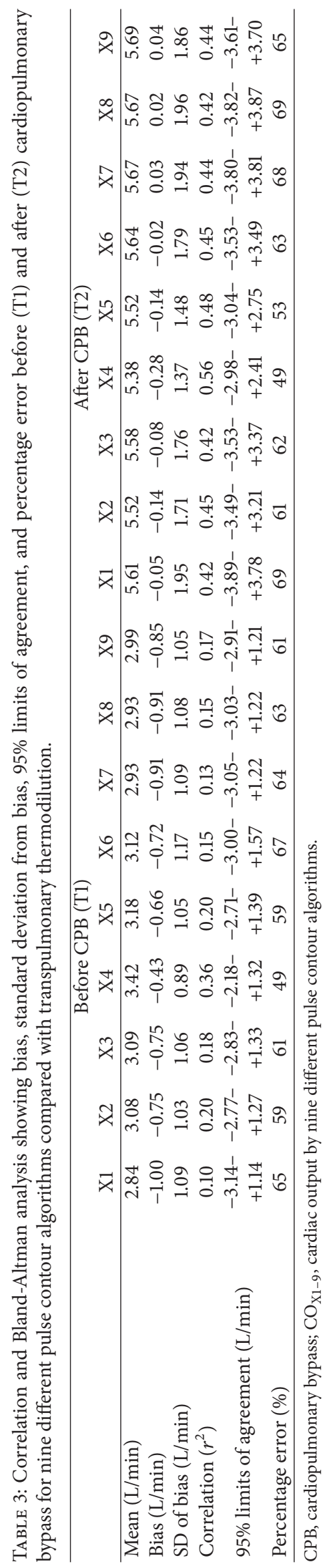




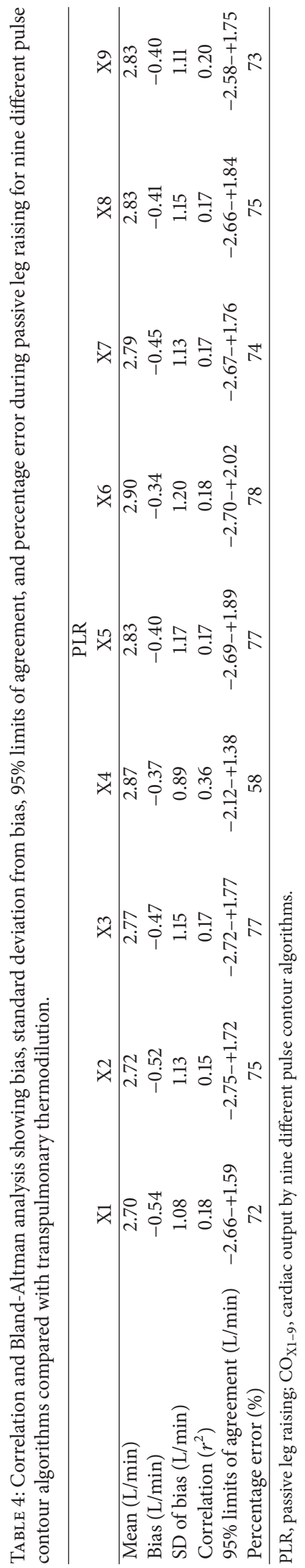


Trends before $\mathrm{CPB} \mathrm{CO}_{\mathrm{X} 1}$

Trends before $\mathrm{CPB} \mathrm{CO}_{\mathrm{X} 2}$

Trends before $\mathrm{CPB} \mathrm{CO}_{\mathrm{X} 3}$

$r^{2}=0.33$

$p<0.0001$

Concordance rate $84 \%$

(Exclusion zone 15\%)

No zone $69 \%$

$$
\begin{aligned}
& r^{2}=0.53 \\
& p<0.0001
\end{aligned}
$$

Concordance rate $88 \%$

(Exclusion zone 15\%)

No zone $76 \%$ $r^{2}=0.49$

$p<0.0001$

Concordance rate $88 \%$

(Exclusion zone 15\%)

No zone $75 \%$

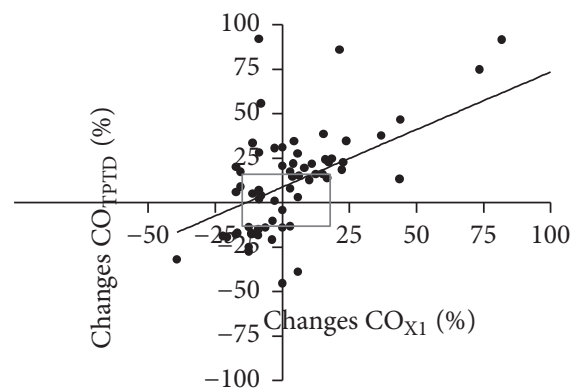

Trends before $\mathrm{CPB} \mathrm{CO}_{\mathrm{X} 4}$

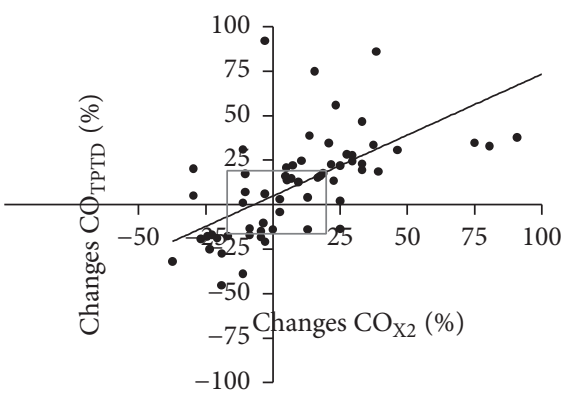

Trends before $\mathrm{CPB} \mathrm{CO}_{\mathrm{X}}$

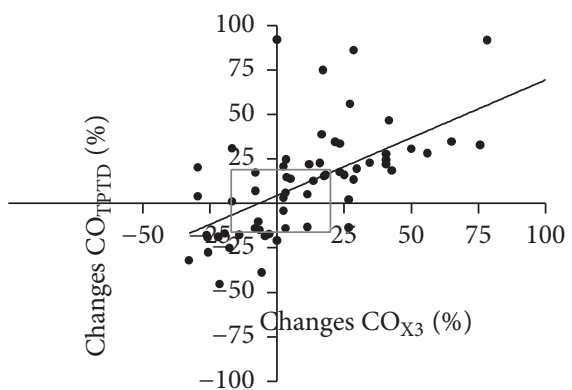

Trends before $\mathrm{CPB} \mathrm{CO}_{\mathrm{X} 6}$ $r^{2}=0.52$

$p<0.0001$

Concordance rate 89\%

(Exclusion zone 15\%)

No zone $77 \%$

$$
r^{2}=0.53
$$

$p<0.0001$

Concordance rate $85 \%$

(Exclusion zone 15\%)

No zone $73 \%$ $r^{2}=0.56$

$p<0.0001$

Concordance rate $88 \%$

(Exclusion zone 15\%)

No zone $72 \%$

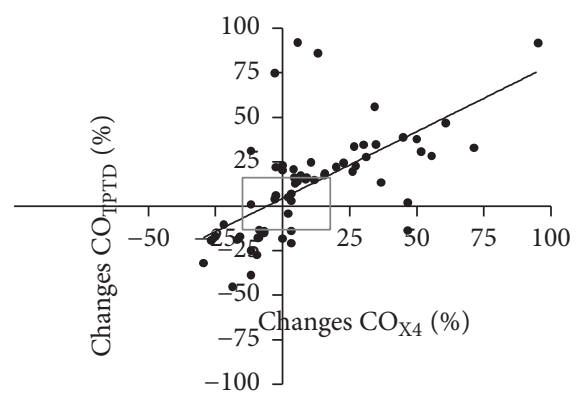

Trends before $\mathrm{CPB} \mathrm{CO}_{\mathrm{X}}$

$r^{2}=0.45$

$p<0.0001$

Concordance rate $80 \%$

(Exclusion zone 15\%)

No zone $70 \%$

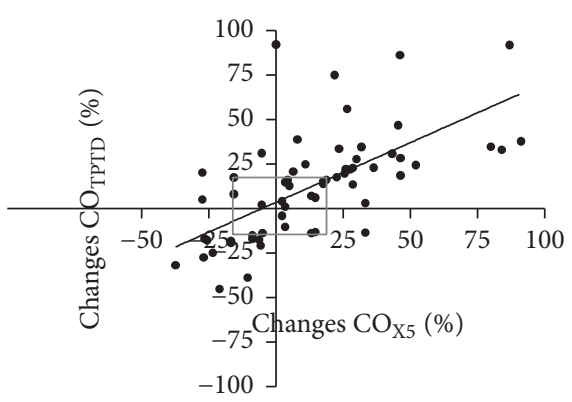

Trends before $\mathrm{CPB} \mathrm{CO}_{\mathrm{X} 8}$

$r^{2}=0.38$

$p<0.0001$

Concordance rate $77 \%$

(Exclusion zone 15\%)

No zone $71 \%$

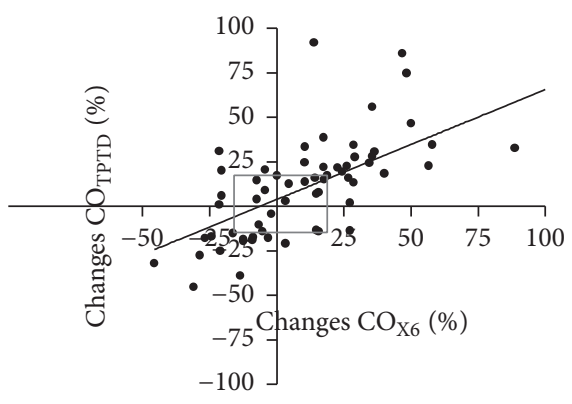

Trends before $\mathrm{CPB} \mathrm{CO}_{\mathrm{X} 9}$
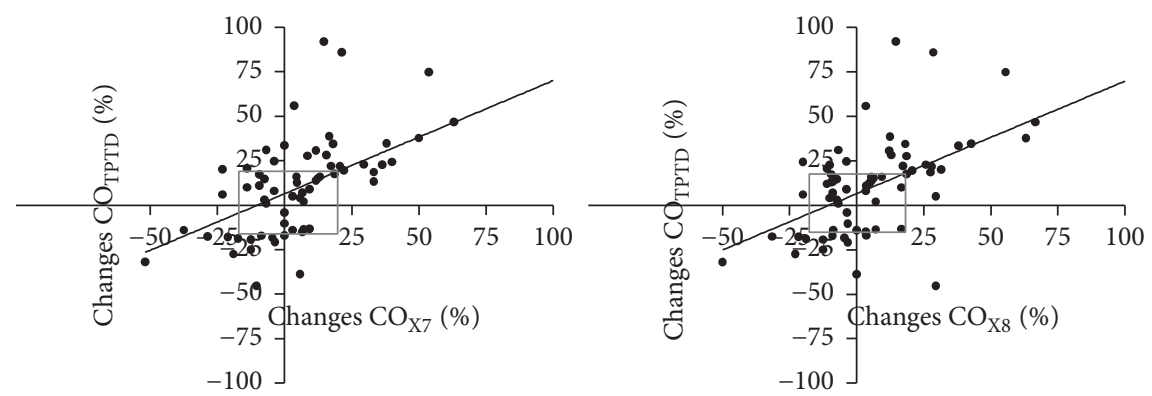

(a)

$r^{2}=0.43$

$p<0.0001$

Concordance rate $84 \%$

(Exclusion zone 15\%)

No zone $71 \%$

FIgure 2: Continued.

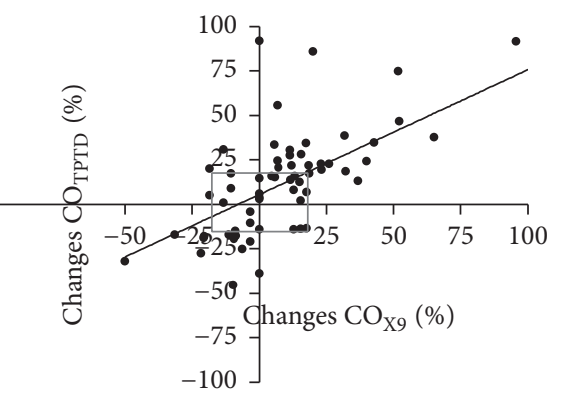


Trends after $\mathrm{CPB} \mathrm{CO}_{\mathrm{X} 1}$

$$
\begin{aligned}
& r^{2}=0.16 \\
& p=0.0137
\end{aligned}
$$

Concordance rate $71 \%$

(Exclusion zone 15\%)

No zone $69 \%$

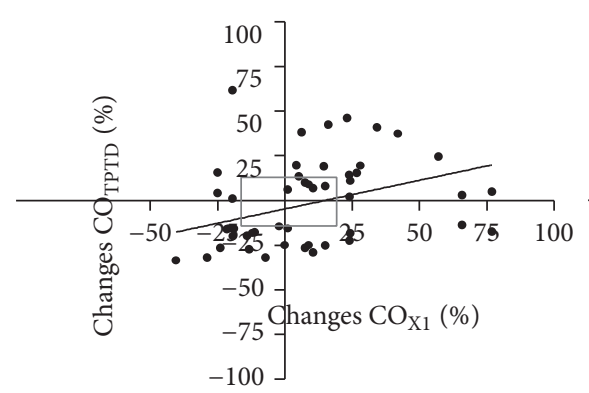

Trends after $\mathrm{CPB} \mathrm{CO}_{\mathrm{X} 4}$

$$
\begin{aligned}
& r^{2}=0.46 \\
& p<0.0001
\end{aligned}
$$

Concordance rate 95\%

(Exclusion zone 15\%)

No zone $86 \%$

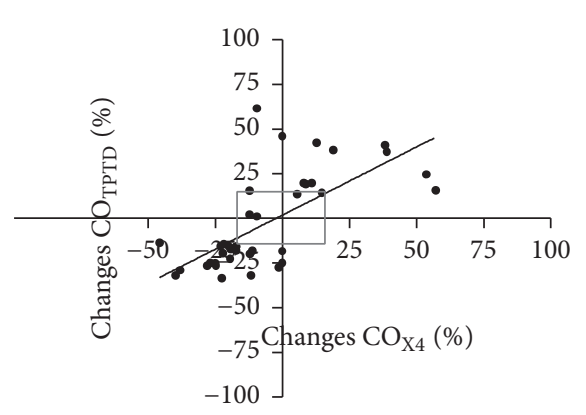

Trends after $\mathrm{CPB} \mathrm{CO}_{\mathrm{X} 7}$

$$
\begin{aligned}
& r^{2}=0.11 \\
& p<0.0001
\end{aligned}
$$

Concordance rate $73 \%$

(Exclusion zone 15\%)

No zone $69 \%$
Trends after $\mathrm{CPB} \mathrm{CO}_{\mathrm{X} 2}$

$$
\begin{aligned}
& r^{2}=0.41 \\
& p<0.0001
\end{aligned}
$$

Concordance rate $90 \%$

(Exclusion zone 15\%)

No zone $80 \%$

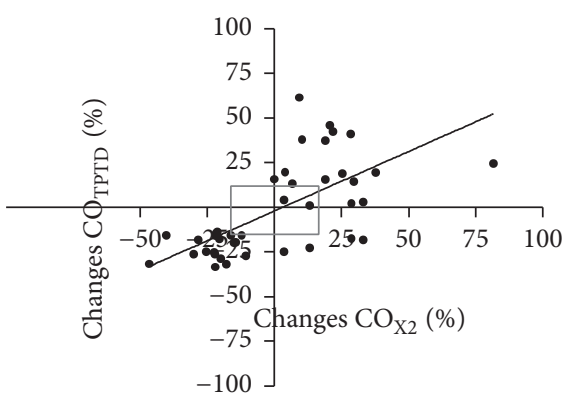

Trends after $\mathrm{CPB} \mathrm{CO}_{\mathrm{X} 5}$

$$
\begin{aligned}
& r^{2}=0.37 \\
& p<0.0001
\end{aligned}
$$

Concordance rate $90 \%$

(Exclusion zone 15\%)

No zone $81 \%$

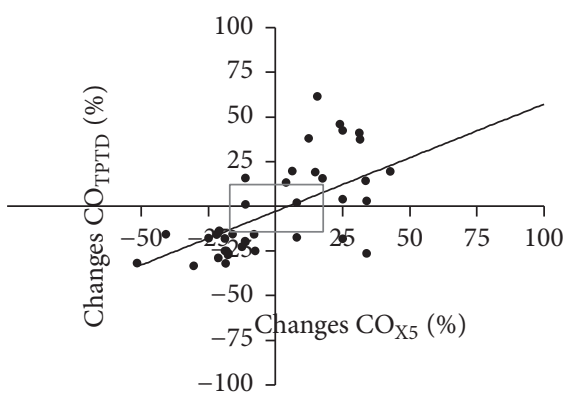

Trends after $\mathrm{CPB} \mathrm{CO}_{\mathrm{X} 8}$

$$
\begin{array}{ll}
r^{2}=0.16 & r^{2}=0.41 \\
p=0.0507 & p<0.0001
\end{array}
$$

Concordance rate $76 \%$

(Exclusion zone 15\%)

No zone $73 \%$

$$
\begin{aligned}
& r^{2}=0.19 \\
& p=0.0061
\end{aligned}
$$

No zone $73 \%$

No zone $71 \%$
Trends after $\mathrm{CPB} \mathrm{CO}_{\mathrm{X} 3}$

$$
r^{2}=0.38
$$$$
p<0.0001
$$

Concordance rate 87\%

(Exclusion zone 15\%)

No zone $79 \%$

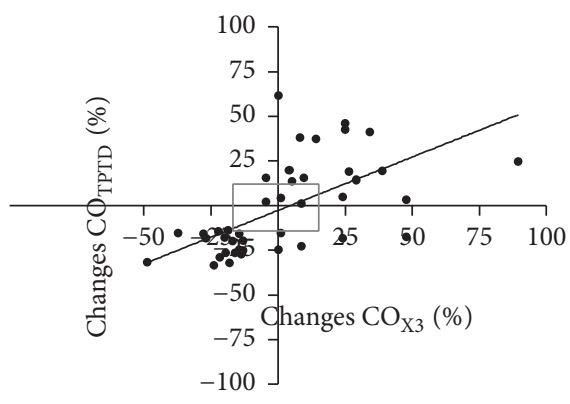

Trends after $\mathrm{CPB} \mathrm{CO}_{\mathrm{X} 6}$

Concordance rate $79 \%$

(Exclusion zone 15\%)

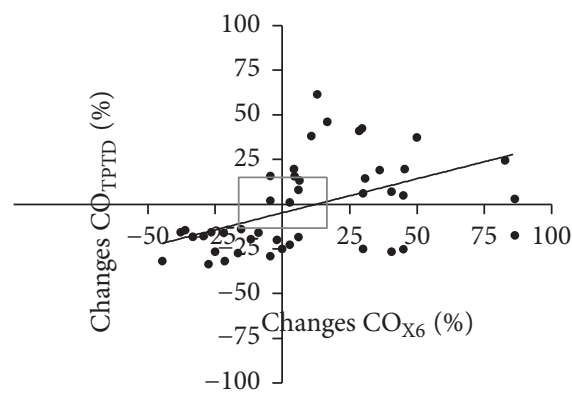

Trends after $\mathrm{CPB} \mathrm{CO}_{\mathrm{X} 9}$

Concordance rate $73 \%$

(Exclusion zone 15\%)
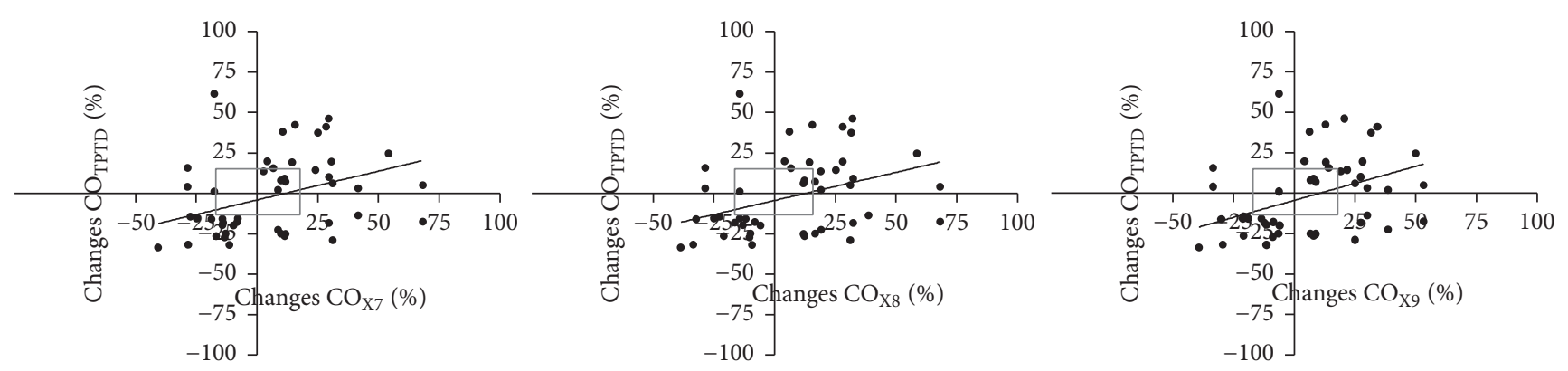

(b)

FIgURE 2: Four-Quadrant Concordance Plots. Percentage changes in cardiac output measured by transpulmonary thermodilution (CO $\left.{ }_{\mathrm{TPTD}}\right)$ and cardiac output measured by nine different pulse contour algorithms $\left(\mathrm{CO}_{\mathrm{X} 1-9}\right)$ before and after cardiopulmonary bypass (CPB). Changes below $15 \%$ (gray rectangle) were excluded from analysis. 


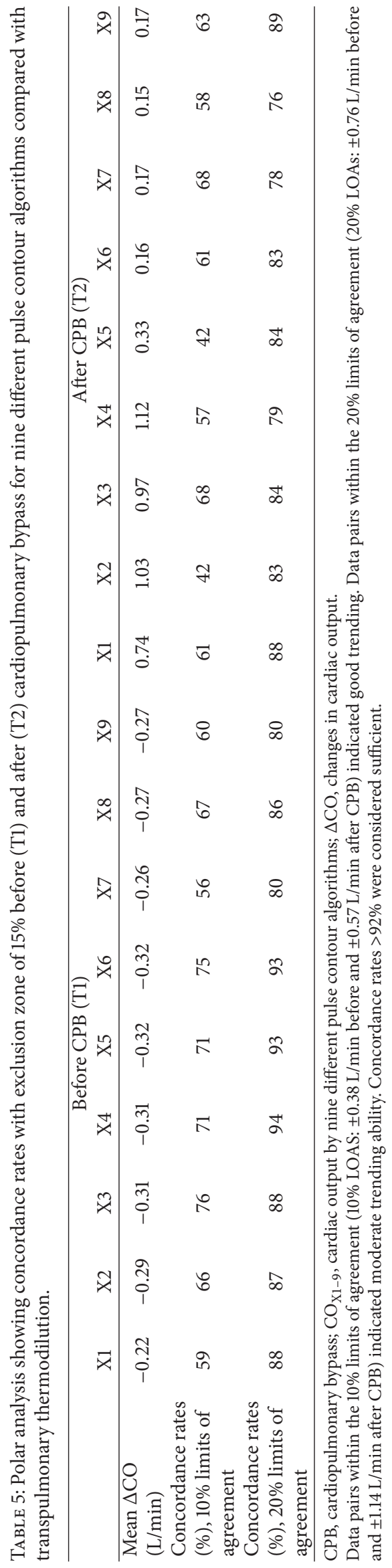


of monitoring systems [28]. In this context, it must be noted that the Liljestrand-Zander model (X4) revealed the best correlation and percentage error (49\% before and after $\mathrm{CPB}$ ) compared to all other pulse contour algorithms. One possible explanation for this result might be the underlying physiological background of arterial pulse wave analysis. As suggested by Otto Frank, the Windkessel model consists of the three vascular properties resistance, compliance, and impedance which influence the arterial waveform analysis [13]. Furthermore, the proportional relation of aortic pulse pressure and SV and their inverse relation to aortic compliance represent the physiological basis of arterial pressure curves [29]. It must be emphasized that the LiljestrandZander model takes the pressure induced varying arterial capacitance as well as the nonlinearity between vascular compliance and arterial pressure into account. Additionally, we observed no correlation between MAP and $\mathrm{CO}_{\text {TPTD }}$ which emphasizes the fact that arterial compliance differed from patient to patient. As mentioned above, aortic compliance is linked to a nonlinear response to arterial pressure and since individual aortic cross sectional area is unknown, these uncertainties could lead to imprecision in determination of $\mathrm{CO}$ by arterial waveform analysis. In this context, it is important to consider that in analogy of Ohm's law CO is directly proportional to MAP and inversely proportional to SVR. Furthermore, these variables are not independent of each other but rather highly interdependent through various control circuits. Therefore, this emphasizes recalibration of pulse contour analysis by thermodilution or Doppler ultrasound to provide maximum accuracy during haemodynamic measurements.

Our findings were supported by other studies dealing with various pulse contour algorithms. For example, Zhang and colleagues investigated five different pulse contour algorithms and observed poor precision and trending ability for all algorithms but the Liljestrand-Zander model performed best. Additional to the esophageal Doppler, the authors used suprasternal Doppler as the reference technique [14]. Other authors compared five different monitor systems based on pulse contour analysis against thermodilution and also reported poor agreement and trending ability [30]. Additionally, further studies dealing with pulse contour algorithms reported detrimental influence of significant changes of blood pressure on accuracy of uncalibrated waveform analysis both in animals and in humans [31-33]. Referring to this, we observed no significant correlation between $\mathrm{CO}_{\mathrm{X} 1-9}$ and MAP in our patient collective. Another important issue concerning accuracy of pulse contour analysis is the position of the arterial catheter. It must be noted that arterial pressure waveforms differ from central to peripheral arteries and devices based on pulse contour analysis typically use the existing radial arterial signal for calculation of $\mathrm{CO}$ [34]. Recent studies could demonstrate a significant impact on the accuracy of uncalibrated pulse contour analysis by the arterial signal source [35, 36].

Another explanation for the observed poor correlation between $\mathrm{CO}_{\mathrm{TPTD}}$ and $\mathrm{CO}_{\mathrm{X} 1-9}$ could be the reference technique, that is, esophageal Doppler, for calibration of the different pulse contour algorithms. Though supplied with an excellent trending ability, the esophageal Doppler is associated with higher bias and percentage error if estimation of absolute values of CO is taken into account [10, 20,37]. This is in line with our findings as we observed moderate correlations and a percentage error of $40 \%$ before and 35\% after $\mathrm{CPB}$ for $\mathrm{CO}_{\mathrm{ED}}$. Interestingly, Zhang and colleagues used two Doppler methods (esophageal and suprasternal) as reference techniques for five different pulse contour algorithms. They observed low concordance rates between suprasternal and esophageal Doppler readings and explained their findings with a redistribution of blood flow due to dopamine administration with consecutive changes in peripheral resistance [14]. Usually Doppler devices calculate aortic diameter by a nomogram and assume that this parameter remains constant. However, the diameter varies with arterial pressure possibly leading to further imprecision [38]. A recent investigation demonstrated improvement of accuracy for esophageal Doppler by estimation of aortic diameter using an M-mode signal [39]. Referring to trending ability, in our study fourquadrant analysis revealed concordance rates of $95 \%$ before and $90 \%$ after $\mathrm{CPB}$ for $\mathrm{CO}_{\mathrm{ED}}$. Concordance rates over $95 \%$ indicate good trending ability, rates between 90 and 95\% are acceptable, and concordance rates below 90\% should be considered as poor trending [20]. Before CPB, all pulse contour algorithms showed concordance rates between 77 and $89 \%$ with highest rates for Liljestrand-Zander (X4). After $\mathrm{CPB}$, concordance rates ranged from 71 to $95 \%$ again with the highest rates for the Liljestrand-Zander algorithm. Polar analysis revealed poor concordance rates for all algorithms before and after CPB if only data within the 10\% LOAs were considered. With respect to the $20 \%$ LOAs, concordance rates ranged between 80 and $94 \%$ with best rates for LiljestrandZander algorithm (X4) before CPB. In contrast, after CPB all pulse contour algorithms revealed concordance rates below $90 \%$. With respect to trending ability, our findings were in agreement with other studies dealing with uncalibrated pulse contour analysis $[11,14,20]$.

We observed a weak but significant correlation between SVR and $\mathrm{CO}_{\mathrm{X} 1-9}$. To evaluate the effect of SVR on the differences of $\mathrm{CO}$ between techniques, we calculated the correlation between the bias of $\mathrm{CO}_{\mathrm{TPTD}}$ and $\mathrm{CO}_{\mathrm{X} 1-9}$ and corresponding SVR as suggested by recent literature [40]. Before $\mathrm{CPB}$, we observed a significant correlation between the bias and SVR only for X1 $\left(r^{2}=0.05, p=0.0061\right), \mathrm{X} 7$ $\left(r^{2}=0.05, p=0.0025\right), \mathrm{X} 8\left(r^{2}=0.05, p=0.0048\right)$, and $\mathrm{X} 9$ $\left(r^{2}=0.04, p=0.0096\right)$. After CPB, we observed no significant correlation suggesting that SVR seems to have no considerable impact on accuracy of $\mathrm{CO}_{\mathrm{X} 1-9}$. With respect to acute hemodynamic changes, we performed a passive leg raising maneuver after induction of anesthesia and before starting surgery. During passive leg raising, all pulse contour algorithms failed interchangeability with the reference technique (percentage error 58-78\%). Taking our findings into account, the Liljestrand-Zander model seems to be the most suitable algorithm for combination with esophageal Doppler and, furthermore, our results confirm the composition of the recently released CardioQ-ODM+ monitor. 
There are some limitations in our study which have to be discussed. Patients with esophageal malformations, hemodynamic instability, and shock or lack of sinus rhythm were excluded. In this context, it must be emphasized that we investigated patients undergoing elective coronary surgery with normal left ventricular function and without continuous catecholamine therapy. Therefore, our results cannot be readily transferred to patients with hemodynamic instability, impaired left ventricular function, low cardiac output, and cardiac arrhythmias or patients receiving continuous highdose inotropic or vasoactive support. Furthermore, interpretation of our results is limited by the absence of an ultrasonic flow probe as the gold standard for estimation of SV. We used the clinical gold standard, transpulmonary thermodilution. Additionally, due to a longer distance between indicator injection and detection compared to pulmonary thermodilution and a drop in central baseline temperature especially after $\mathrm{CPB}$, transpulmonary thermodilution might have some limitations [17]. Future studies should investigate these pulse contour algorithms in different patient collectives suffering from severe cardiovascular diseases and using a higher calibration frequency through a reference technique.

In conclusion, we observed poor agreement and trending ability for all nine pulse contour algorithms before and after CPB. Furthermore, all pulse contour algorithms failed to meet criteria of interchangeability during a passive leg raising maneuver. However, the Liljestrand-Zander model revealed the best reliability and trending ability compared with transpulmonary thermodilution. One reason for this observation could be the fact that the Liljestrand-Zander algorithm takes the nonlinearity between vascular compliance and arterial pressure into account. Our findings suggest that monitor systems based on esophageal Doppler combined with pulse contour analysis should be calibrated immediately when hemodynamic changes occur. However, as we excluded patients with hemodynamic instability or shock, this limitation prevents generalization of our results.

\section{Competing Interests}

Dr. Bein is a member of the medical advisory board of Pulsion Medical Systems (Munich, Germany) and has received honoraria for consulting and giving lectures. Dr. Gruenewald has received honoraria from GE Healthcare (Munich, Germany) for giving lectures. Dr. Renner has received honoraria from Edwards Lifesciences (Irvine, CA, USA) for giving lectures. All other authors declare that there is no conflict of interests regarding the publication of this paper.

\section{Acknowledgments}

The authors are indebted to Bernd Kuhr for excellent technical assistance and logistic support.

\section{References}

[1] T. W. L. Scheeren, C. Wiesenack, H. Gerlach, and G. Marx, "Goal-directed intraoperative fluid therapy guided by stroke volume and its variation in high-risk surgical patients: A Prospective Randomized Multicentre Study," Journal of Clinical Monitoring and Computing, vol. 27, no. 3, pp. 225-233, 2013.

[2] M. Singer, "Oesophageal doppler," Current Opinion in Critical Care, vol. 15, no. 3, pp. 244-248, 2009.

[3] M. R. Lopes, M. A. Oliveira, V. O. S. Pereira, I. P. B. Lemos, J. O. C. Auler Jr., and F. Michard, "Goal-directed fluid management based on pulse pressure variation monitoring during high-risk surgery: a pilot randomized controlled trial," Critical Care, vol. 11, article R100, 2007.

[4] S. Ghosh, B. Arthur, and A. A. Klein, "NICE guidance on CardioQ ${ }^{\mathrm{TM}}$ oesophageal Doppler monitoring," Anaesthesia, vol. 66, no. 12, pp. 1081-1083, 2011.

[5] M. A. Hamilton, M. Cecconi, and A. Rhodes, "A systematic review and meta-analysis on the use of preemptive hemodynamic intervention to improve postoperative outcomes in moderate and high-risk surgical patients," Anesthesia and Analgesia, vol. 112, no. 6, pp. 1392-1402, 2011.

[6] A. P. Wheeler, G. R. Bernard, B. T. Thompson et al., "Pulmonary-artery versus central venous catheter to guide treatment of acute lung injury," The New England Journal of Medicine, vol. 354, no. 21, pp. 2213-2224, 2006.

[7] J. D. Sandham, R. D. Hull, R. F. Brant et al., "A randomized, controlled trial of the use of pulmonary-artery catheters in highrisk surgical patients," The New England Journal of Medicine, vol. 348, no. 1, pp. 5-14, 2003.

[8] S. McGuinness and R. Parke, "Using cardiac output monitoring to guide perioperative haemodynamic therapy," Current Opinion in Critical Care, vol. 21, no. 4, pp. 364-368, 2015.

[9] M. Cannesson, G. Pestel, C. Ricks, A. Hoeft, and A. Perel, "Hemodynamic monitoring and management in patients undergoing high risk surgery: a survey among North American and European anesthesiologists," Critical Care, vol. 15, no. 4, article R197, 2011.

[10] P. J. Peyton and S. W. Chong, "Minimally invasive measurement of cardiac output during surgery and critical care: a metaanalysis of accuracy and precision," Anesthesiology, vol. 113, no. 5, pp. 1220-1235, 2010.

[11] T. Schlöglhofer, H. Gilly, and H. Schima, "Semi-invasive measurement of cardiac output based on pulse contour: a review and analysis," Canadian Journal of Anesthesia, vol. 61, no. 5, pp. 452-479, 2014.

[12] O. Broch, J. Carbonell, C. Ferrando et al., "Accuracy of an autocalibrated pulse contour analysis in cardiac surgery patients: a bi-center clinical trial," BMC Anesthesiology, vol. 15, article 171, 2015.

[13] K. Sagawa, R. K. Lie, and J. Schaefer, "Translation of Otto Frank’s paper 'Die Grundform des Arteriellen Pulses,' Zeitschrift fur Biologie, vol. 37, pp. 483-526, 1899, Journal of Molecular and Cellular Cardiology, vol. 22, no. 3, pp. 253-277, 1990.

[14] J. Zhang, L. A. H. Critchley, and L. Huang, "Five algorithms that calculate cardiac output from the arterial waveform: a comparison with doppler ultrasound," British Journal of Anaesthesia, vol. 115, no. 3, pp. 392-402, 2015.

[15] J. X. Sun, A. T. Reisner, M. Saeed, T. Heldt, and R. G. Mark, "The cardiac output from blood pressure algorithms trial," Critical Care Medicine, vol. 37, no. 1, pp. 72-80, 2009.

[16] X. Monnet and J.-L. Teboul, "Passive leg raising: five rules, not a drop of fluid!," Critical Care, vol. 19, article 18, 2015. 
[17] P.-J. Hofkens, A. Verrijcken, K. Merveille et al., "Common pitfalls and tips and tricks to get the most out of your transpulmonary thermodilution device: results of a survey and state-ofthe-art review," Anaesthesiology Intensive Therapy, vol. 47, no. 2, pp. 89-116, 2015.

[18] J. M. Bland and D. G. Altman, "Agreement between methods of measurement with multiple observations per individual," Journal of Biopharmaceutical Statistics, vol. 17, no. 4, pp. 571-582, 2007.

[19] L. A. H. Critchley and J. A. J. H. Critchley, "A meta-analysis of studies using bias and precision statistics to compare cardiac output measurement techniques," Journal of Clinical Monitoring and Computing, vol. 15, no. 2, pp. 85-91, 1999.

[20] L. A. Critchley, A. Lee, and A. M.-H. Ho, "A critical review of the ability of continuous cardiac output monitors to measure trends in cardiac output," Anesthesia and Analgesia, vol. 111, no. 5, pp. 1180-1192, 2010.

[21] T. Bossert, J. F. Gummert, H. B. Bittner et al., "Swan-Ganz catheter-induced severe complications in cardiac surgery: right ventricular perforation, knotting, and rupture of a pulmonary artery," Journal of Cardiac Surgery, vol. 21, no. 3, pp. 292-295, 2006.

[22] R. M. Pearse, R. P. Moreno, P. Bauer et al., "Mortality after surgery in Europe: a 7 day cohort study," The Lancet, vol. 380, no. 9847, pp. 1059-1065, 2012.

[23] S. T. Gurgel and P. Do Nascimento Jr., "Maintaining tissue perfusion in high-risk surgical patients: a systematic review of randomized clinical trials," Anesthesia and Analgesia, vol. 112, no. 6, pp. 1384-1391, 2011.

[24] M. S. Goepfert, H. P. Richter, C. Zu Eulenburg et al., "Individually optimized hemodynamic therapy reduces complications and length of stay in the intensive care unit: a prospective, randomized controlled trial," Anesthesiology, vol. 119, no. 4, pp. 824-836, 2013.

[25] K. Suehiro, K. Tanaka, T. Funao, T. Matsuura, T. Mori, and K. Nishikawa, "Systemic vascular resistance has an impact on the reliability of the Vigileo-FloTrac system in measuring cardiac output and tracking cardiac output changes," British Journal of Anaesthesia, vol. 111, no. 2, pp. 170-177, 2013.

[26] B. Bein, P. Meybohm, E. Cavus et al., "The reliability of pulse contour-derived cardiac output during hemorrhage and after vasopressor administration," Anesthesia \& Analgesia, vol. 105, no. 1, pp. 107-113, 2007.

[27] M. Gruenewald, J. Renner, P. Meybohm, J. Höcker, J. Scholz, and B. Bein, "Reliability of continuous cardiac output measurement during intra-abdominal hypertension relies on repeated calibrations: an experimental animal study," Critical Care, vol. 12, no. 5, article no. R132, 2008.

[28] M. Sander, C. D. Spies, H. Grubitzsch, A. Foer, M. Müller, and C. von Heymann, "Comparison of uncalibrated arterial waveform analysis in cardiac surgery patients with thermodilution cardiac output measurements," Critical Care, vol. 10, no. 6, article R164, 2006.

[29] O. Vardoulis, T. G. Papaioannou, and N. Stergiopulos, "On the estimation of total arterial compliance from aortic pulse wave velocity," Annals of Biomedical Engineering, vol. 40, no. 12, pp. 2619-2626, 2012.

[30] R. B. P. de Wilde, J. J. Schreuder, P. C. M. van den Berg, and J. R. C. Jansen, "An evaluation of cardiac output by five arterial pulse contour techniques during cardiac surgery," Anaesthesia, vol. 62 , no. 8 , pp. $760-768,2007$.
[31] E. S. Cooper and W. W. Muir, "Continuous cardiac output monitoring via arterial pressure waveform analysis following severe hemorrhagic shock in dogs," Critical Care Medicine, vol. 35, no. 7, pp. 1724-1729, 2007.

[32] S. Eleftheriadis, Z. Galatoudis, V. Didilis et al., "Variations in arterial blood pressure are associated with parallel changes in FlowTrac/Vigileo-derived cardiac output measurements: a prospective comparison study," Critical Care, vol. 13, no. 6, p. R179, 2009.

[33] O. Broch, J. Renner, J. Höcker et al., "Uncalibrated pulse power analysis fails to reliably measure cardiac output in patients undergoing coronary artery bypass surgery," Critical Care, vol. 15, no. 1, article R76, 2011.

[34] K. Takazawa, H. Kobayashi, N. Shindo, N. Tanaka, and A. Yamashina, "Relationship between radial and central arterial pulse wave and evaluation of central aortic pressure using the radial arterial pulse wave," Hypertension Research, vol. 30, no. 3, pp. 219-228, 2007.

[35] S. Schramm, E. Albrecht, P. Frascarolo, P.-G. Chassot, and D. R. Spahn, "Validity of an arterial pressure waveform analysis device: does the puncture site play a role in the agreement with intermittent pulmonary artery catheter thermodilution measurements?" Journal of Cardiothoracic and Vascular Anesthesia, vol. 24, no. 2, pp. 250-256, 2010.

[36] S. Lorsomradee, S. Lorsomradee, S. Cromheecke, and S. G. De Hert, "Uncalibrated arterial pulse contour analysis versus continuous thermodilution technique: effects of alterations in arterial waveform," Journal of Cardiothoracic and Vascular Anesthesia, vol. 21, no. 5, pp. 636-643, 2007.

[37] P. M. Dark and M. Singer, "The validity of trans-esophageal Doppler ultrasonography as a measure of cardiac output in critically ill adults," Intensive Care Medicine, vol. 30, no. 11, pp. 2060-2066, 2004.

[38] G. J. Langewouters, K. H. Wesseling, and W. J. A. Goedhard, "The pressure dependent dynamic elasticity of 35 thoracic and 16 abdominal human aortas in vitro described by a five component model," Journal of Biomechanics, vol. 18, no. 8, pp. 613-620, 1985.

[39] X. Monnet, D. Chemla, D. Osman et al., "Measuring aortic diameter improves accuracy of esophageal Doppler in assessing fluid responsiveness," Critical Care Medicine, vol. 35, no. 2, pp. 477-482, 2007.

[40] E. K. Junttila, J. K. Koskenkari, P. P. Ohtonen, and T. I. AlaKokko, "Uncalibrated arterial pressure waveform analysis for cardiac output monitoring is biased by low peripheral resistance in patients with intracranial haemorrhage," British Journal of Anaesthesia, vol. 107, no. 4, pp. 581-586, 2011. 


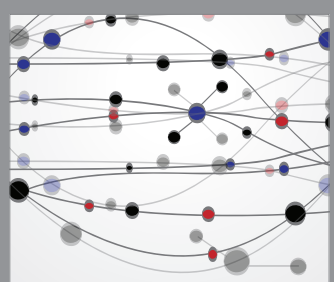

The Scientific World Journal
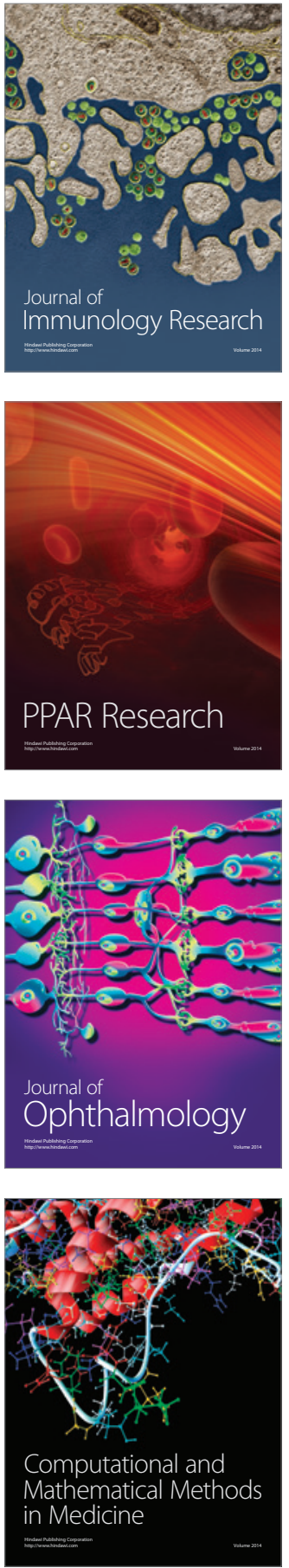

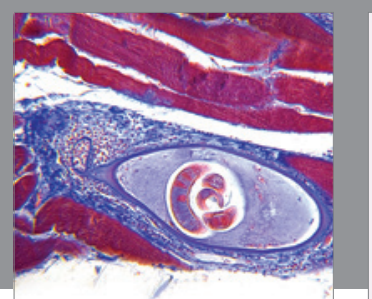

Gastroenterology Research and Practice

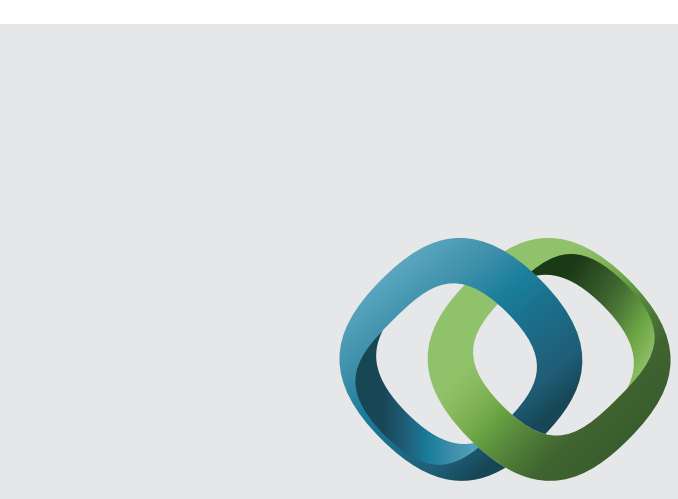

\section{Hindawi}

Submit your manuscripts at

http://www.hindawi.com
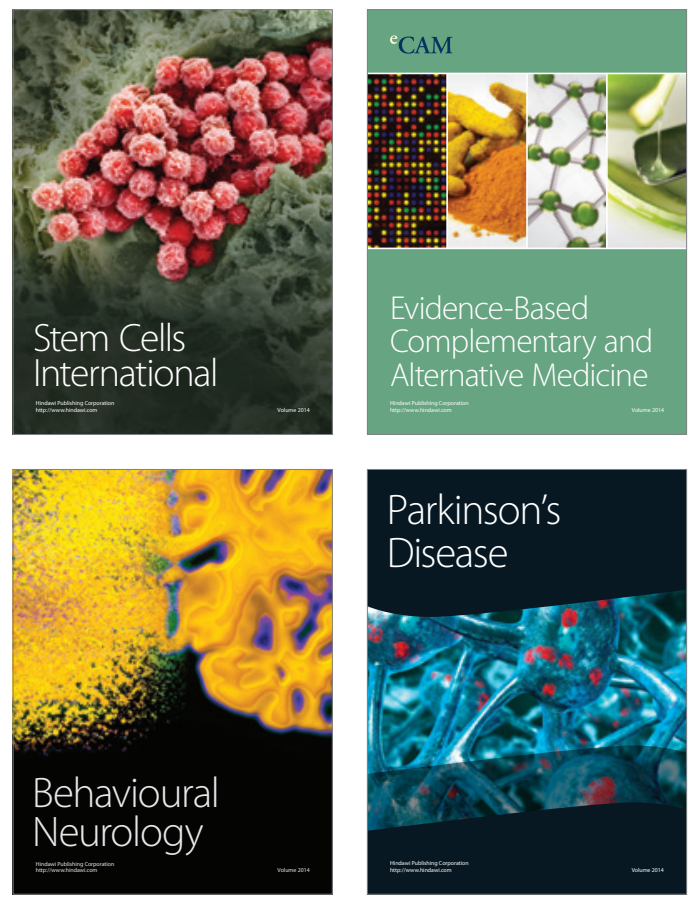
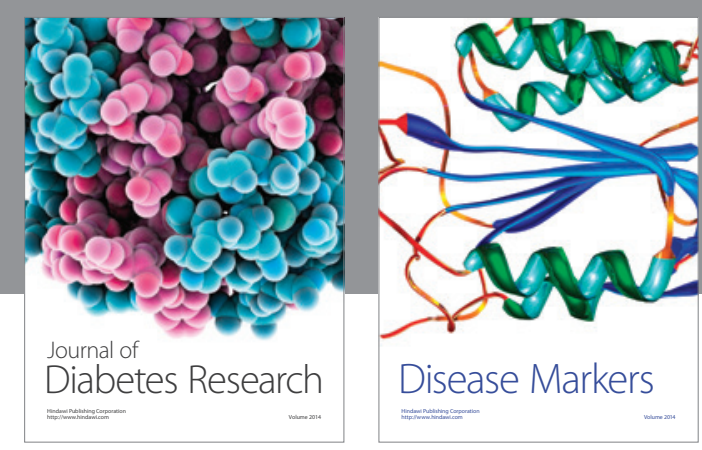

Disease Markers
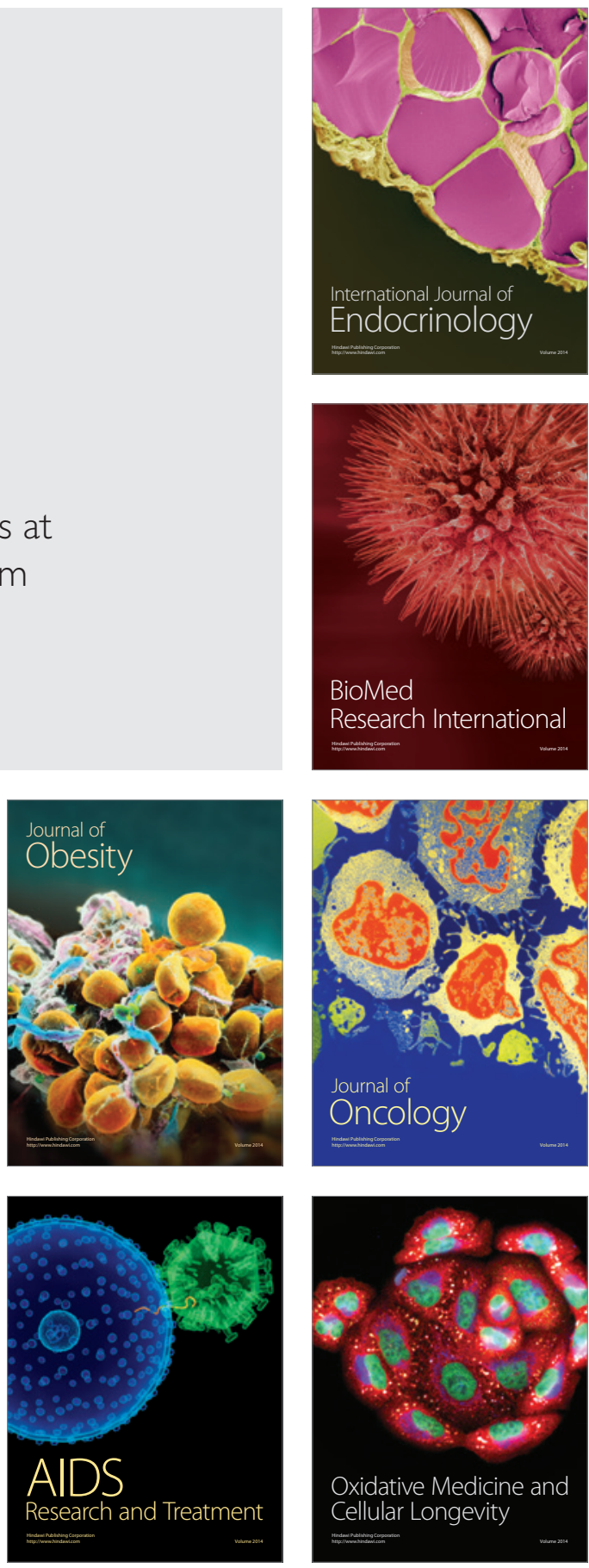